\title{
8. The Distributive Forces in Digital Capitalism: Some Empirical Illustrations
}

There are three levels particularly relevant for an understanding of digital capitalism: the company level (GAFAM and the platform economy), the digital technologies and their potential, and work itself. In this chapter, I consider these three levels-as a test case, so to speak-through the distributive-force lens. My aim is not to replace the corresponding approaches and interpretations that exist already but, at most, to complement them. Above all, I do not here seek to present a profound empirical study of the processes and objects concerned. Instead, I will test the adequacy of the distributive-force lens: does this analytical approach really help us in gaining a new understanding of empirical phenomena and thus of what is new about digital capitalism? Or is this nothing but a purely theoretical analytical concept? These questions cannot be comprehensively answered here-let alone with regard to each and every empirical detail-nor is this my intention. I will illustrate, rather, what and how much the distributive-force perspective can teach us about what is new and unprecedented in digital capitalism.

To start off (Chapter 8.1), I compare the key performance indicators (KPI) of the GAFAM corporations, seeing as they are regarded as the most important protagonists in almost every analysis of digital capitalism. This conventional economic inspection, however, neither suffices to explain the differences in the figures between the companies considered nor does it contribute anything substantial to an understanding of digital capitalism. Correspondingly, the analysis then shifts to a political-economic perspective as developed in this book. Based on the theoretical reflections regarding the blind spots of value realisation (Chapter 5), the second section (Chapter 8.2) is about 'brushing across' the KPI and pinpointing the catalysts for the promised market expansion: the corresponding empirical answers include venture capital, or risk capital, as well as patterns and strategies of ubiquitous consumption. This gives us the opportunity, in a third step, to demonstrate, based on the three theoretically expounded distributive forces (see Chapter 6), that the digital business models of GAFAM and platform providers (as well as a highly diverse range of digital technologies, albeit ones closely bound up with production in the form of Industry 4.0) are unmistakeably aimed at value realisation, not value generation, and combine a wide variety of distributive forces. In this 
context, we will take a closer look at Amazon (Chapter 8.3)—which constitutes, from the perspective of the distributive-force approach, a case apart and a new form of commercial (or merchant) capital distinctive of digital capitalism.

\subsection{GAFAM and the platform economy}

Gadgets like smartphones or tablets aside, platforms - in all their different forms and variations - are without question the most visible and common everyday phenomenon of current digitalisation. As discussed earlier (see Chapter 2.4), it may therefore make perfect sense to speak of platform capitalism, if we are analysing these platforms in particular. What is less justifiable, however, is to transfer this term, with claims to comprehensive validity, to social and economic development as a whole. For, as significant as platforms may be, they cannot be equated with digital capitalism. Nor are they all the same, even though the respective digital infrastructure is always platform-like (but isn't everything on the Internet?), and they can pursue very different business models. Besides, platforms cannot simply be equated with the companies often referred to by the acronym GAFAM. Not all companies that are part of the digital economy and whose shares are top-ratedat least from an analytical vantage point-have attained this status primarily or exclusively through platform activities. This forces us to differentiate.

Digital capitalism is often referred to synonymously with (or in contradistinction to) the no less ostentatious term 'platform capitalism'. But what actually counts as a platform? And why? To Shoshana Zuboff (2019), platforms represent the base of Surveillance Capitalism. Ulrich Dolata sees two functions converging in Internet corporations: not only the structuring and curating of social relations and social behaviour, but also the organisation and regulation of markets by private economic actors: he writes that "[...] their operators act as behavior-shaping mediators and curators of private and public life in the Internet. Privatization, curation, and commodification are what comprise the actual novelty of the commercial platforms on the Internet and what set them apart from their predecessors." (Dolata 2019: 187)

One helpful dimension for differentiating platforms is the use of labour power: Martin Kenney and John Zysman (2018b: 7-8), for example, distinguish platforms by the type of employment (from permanent contracts to no contracts, passing via project-based contracts), the form of compensation (from salaries and share options to the free use of a service), working conditions (from excellent to highly precarious) and the labour process (from creative work to routine tasks, from project-based work to indirect labour via use). This analytical lens allows us to ascertain whether, where and by whom any value is generated on or via these platforms. 
When it comes to the mechanisms of value realisation, the distinction in terms of range of services on offer as introduced by Dolata (2019) appears useful. He distinguishes between search platforms (Google), networking and messaging platforms (Facebook, Instagram, Twitter etc.), media platforms (e.g. YouTube, Netflix or Spotify), commercial (retail) platforms (Amazon, Alibaba or Zalando), ridesharing platforms (e.g. Uber), travel and accommodation (e.g. Airbnb or booking.com) or dating platforms (Parship etc.) as well as cloud platforms (e.g. Amazon, Web Services) and, finally, platforms for crowdsourcing and crowdfunding such as Mechanical Turk or Kickstarter (see ibid.: 183).

Both proposed typologies are productive and extremely helpful for the empirical research on platforms and their different forms. That said, they do somewhat neglect the demand side: who has the need, and why, to work on or for one platform or another (labour force / user perspective)? Who is willing, and why, to pay large sums of money to platforms for their services (management perspective)? This is all the more surprising given that Ulrich Dolata (2019) does in fact point out that the aggressive expansion of platforms entails fragile business models and fierce competition and-further-that creativity regarding business models is limited to ones that we have known since the Internet was first commercialised but which are now reaching their limits: advertising, subscription models and agency fees or commissions (see ibid.: 187-188).

While engaging with the issue of platforms, I will continue to pursue this question of value realisation a bit further and relate it to the distributive forces. To this end, we shall first inspect the platforms in more detail and then turn to their central lifeline-venture capital investment. I will limit myself to the five GAFAM corporations (Google, Amazon, Facebook, Apple, Microsoft) and focus on the management perspective.

I thereby intentionally exclude those business enterprises which are, in the sense of Dolata (2019), pure matching platforms. That is not to say that, for example, Airbnb or Uber represent somehow less interesting cases from the distributive-force perspective-on the contrary: precisely because they have completely withdrawn from what Karl Marx refers to as the 'ownership of the means of production' and what used to be the most characteristic feature of a capitalist or a capitalist enterprise, there would certainly be much to discuss in this regard. Nor will I consider crowdsourcing and crowdfunding platforms here. Unlike Dolata, who refers to both Mechanical Turk (a crowdwork platform operated by Amazon that specialises in micro-tasks) and Kickstarter as crowdfunding platforms, I consider it imperative, from a distributive-force perspective, to distinguish between these two types:

Crowdsourcing platforms are geared towards one particular commodity: labour power. Essentially, they promise client companies nothing less than the end of the transformation problem (i.e. the efforts towards ensuring the use of the 
purchased labour power). Historically, these platforms have, so to speak, 'freed' labour for a third time. Karl Marx had referred to wage labour as 'free in a double sense': workers are free to sell their labour power (in contrast to slaves or serfs), but also free of owning any means of production (and thus dependent on selling their own labour power). In crowdwork, you no longer sell the commodity labour power, and you are now also freed from a work contract and workplace control. And free indeed to bring your own means of production (computer, software, Internet access) - and this, again in a double sense, simultaneously represents the precondition for participating in the new liberation. From this angle, crowdwork and ridesharing platforms-which Dolata regards as different types-would appear ultimately rather similar. Besides, crowdworkers express very much the same notions of fairness as normal wage earners do (see Pfeiffer/Kawalec 2020).

Crowdfunding platforms, by contrast, are a typical example of the many grassroots approaches that have emerged time and again over the history of the Internet, only to end up as a business model with new and entirely different objectives. Originally, crowdfunding platforms were meant to help people with good ideas but no capital or ownership of means of production to become entrepreneurs. This was supposed to free them from having to collect the start-up capital from profit-oriented venture capital investors or security-oriented banks and allow them to collect the necessary funds from a large number of micro-investors or via pre-orders instead. Those applying for funding on the major platforms of this type (Indiegogo and Kickstarter) these days often include already established companies that are simply testing the market suitability of one of their product variants (the more funding, the more subsequent market success can be expected) and are thereby able to reduce to zero the risk of failed value realisation, at least for the first production cycle.

These questions are all quite fascinating and, when considered from the distributive-force perspective, certainly do allow for new insights regarding these two variants of platforms. Nevertheless, here I will limit myself to GAFAM, heeding the advice from Kenney and Zysman (2018b) to clearly distinguish between platform companies and the platform itself. For example, Google represents a search platform, fully in Dolata's sense, and yet Google LLC, or Alphabet Inc. (really, it would have to be AAFAM, not GAFAM), as a corporation, also owns the media platform YouTube. Besides, I am not seeking to elaborate a detailed typology of platform models but rather to develop new and other levels for an understanding of digital capitalism by adopting the distributive-force perspective elaborated in these pages. To this end, it is more conducive to compare different companies that are paradigmatic of digital capitalism than different platform types. 
Fig. 5: Key performance indicators (KPI) of GAFAM and other companies

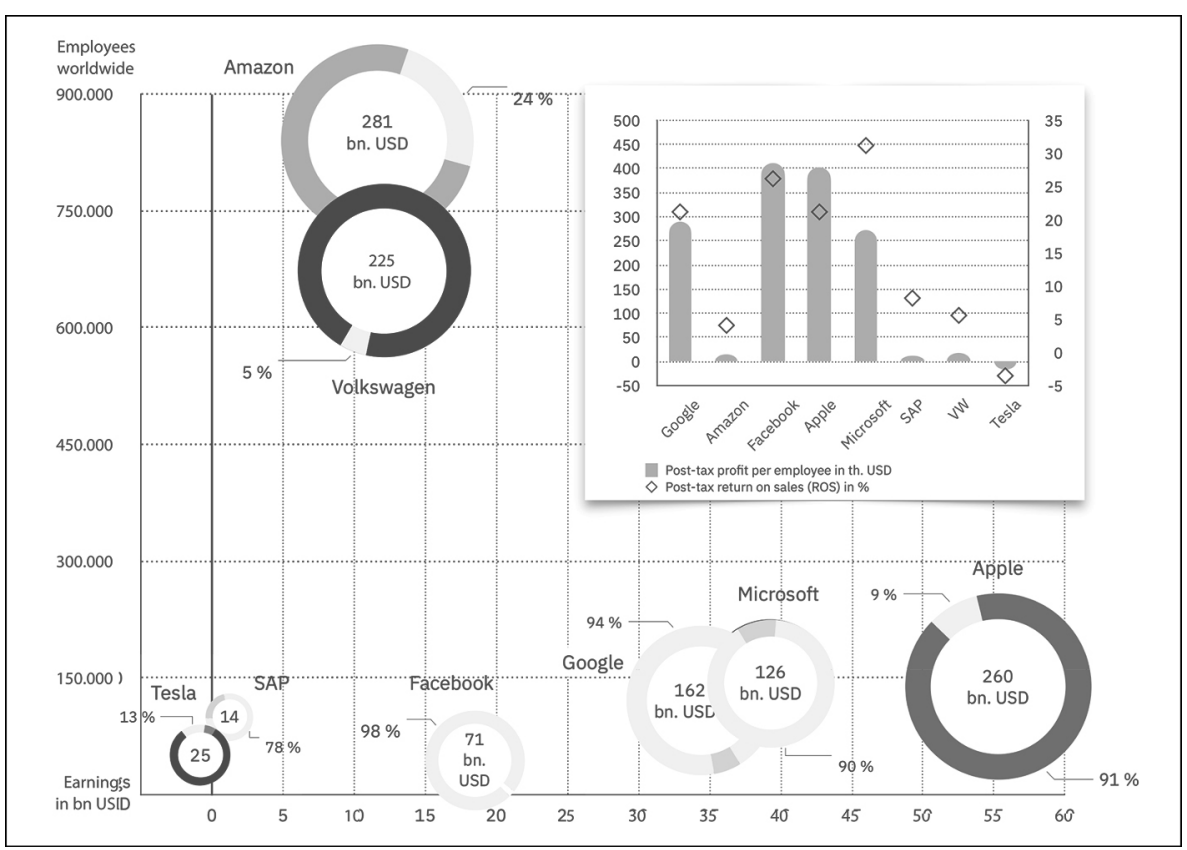

Data basis: Annual reports of Alphabet (2020), Amazon (2020), Apple (2019), Facebook (2020a), Microsoft (2019), SAP (2020), Tesla (2020), Volkswagen (Volkswagen AC 2020).

To start off, let us consider these companies with a view to their KPI. The large chart in Fig. 5 visualises data based on the 2015 annual business reports of the GAFAM companies, (Alphabet 2020; Amazon 2020; Apple 2019; Facebook 2020a; Microsoft 2019), ${ }^{1}$ complemented by figures for SAP, Tesla and Volkswagen. ${ }^{2}$ The

1 The data used here are based on the total data available at the end of the calendar year 2019; minor inconsistencies with other accounts may owe to the fact that financial years in some cases differ from the calendar year; Apple's fiscal year, for example, ends at the end of September, and Microsoft's at the end of June. My own representations and ratio calculations are based on the companies' annual reports cited in the text (as of December 2019), in part complemented by data taken from Ulrich Dolata (2019: 185) and data pertaining to the data-driven shares of revenue as according to LSPdigital (Katschker 2020).

2 This is based on the numbers, indicated in euros, contained in the annual reports for 2019 (SAP 2020; Volkswagen AC 2020)—converted to US dollars using the online currency calculator on finanzen.net and the given exchange rate on 31 December 2019-as well as data from the annual report issued by Tesla for the same fiscal year (2020). Needless to say, figures from annual business reports provide only a rough overview: not only are they optimised in terms of tax efficiency and with a view to stock market regulations and shareholder interests, but the multiform net- 
diameter of the rings in the chart signals the companies' revenue in billions of US dollars; their stated net earnings (in billions of US dollars) are indicated by their position on the $\mathrm{x}$-axis and their number of employees worldwide by the $\mathrm{y}$-axis. Furthermore, the small circular charts inside the rings, based on estimates by data analytics company LSPdigital (Katschker 2020) as well as my own, indicate the share of data-driven revenue. ${ }^{3}$ The small chart in the top right shows the calculated ratios of per capita earnings per employee and the return on sales (post-tax profit share of total revenue). Or, in other words, what is depicted here as a ratio is the extent of successful value realisation on the market. All subsequently represented economic data intentionally pertain to the business year 2019 so as to avoid any distortions owing to the coronavirus crisis. ${ }^{4}$

Intuitively, most people would probably expect Google (or Alphabet 2020) to come out in the lead from a comparison of the different companies considered here. After all, some 118,899 employees generate 94 of the company's data-driven revenue. A total of $\$ 134.8$ billion, or 83.9 per cent of the company's total revenue, is declared as advertising revenues (see Alphabet 2020). At $\$ 161.9$ billion in annual revenue,

work structures of subsidiary companies and outsourcing used for services essential to the business model likewise allow us only a partial insight into their actual operations. However, since all the companies considered are likely to pursue similar strategies, we can be optimistic about discerning certain tendencies nonetheless-which is all we seek to achieve at this point.

3 Based on SAP's business report (2020: 13), the company's data-driven revenues amount to 78 per cent of total revenue (or $€ 12.7$ billion in 'product sales' of the $€ 16.2$ billion total revenue). The figure for Volkswagen is only a rough estimate; it is likely that financial services (15 per cent of total revenue) and the vehicle segment ( 85 per cent of total revenue) also entail, at least in part, data-driven revenues, but these are not broken down explicitly in the report and they are probably so strongly integrated in real terms that these activities would hardly function as a business model in its own right. Here we rely on a rough estimate of a share of around five per cent of total revenue.

4 This entails additional income particularly for Amazon, allowing Jeff Bezos what must be an historically unprecedented leap in wealth: even though he was already the richest person on the planet, he actually increased his net wealth by $\$ 13$ billion in just one day in July of $2020-$ the greatest one-day increase in an individual's wealth ever recorded since the inception of the Bloomberg billionaire index (see Pitcher 2020). All of this occurred, of course, against the backdrop of a US economy that has been declining ever since the global economic crisis. Jeff Bezos's personal wealth is greater than the value of companies such as Exxon Mobil, Nike or McDonald's (see ibid.). Besides Bezos, there are also other US billionaires who have greatly benefited from the Covid-19 pandemic (see Collins et al. 2020: 10-15). Moreover, quarterly reports for autumn 2020the first to actually reflect the impact of the first wave of coronavirus infections-confirm that revenues and stock ratings were strongly influenced by the pandemic (or, at least indicate that this is the common interpretation among businesses and analysts). According to a compilation produced by Business Insider (Holmes 2020), the numbers for GAFA companies were mostly on the increase, even exceeding expectations: Coogle/Alphabet recorded a rise of about 14 per cent compared to the previous year; for Amazon, the increase was 37 per cent, for Facebook 22 per cent (despite slightly declining user numbers), and for Apple around 19 per cent. 
however, Google ranks behind Amazon and Apple, and, at $\$ 34.3$ billion in net earnings, behind Apple and Microsoft. Google also lags far behind Apple with regard to profit per employee, at $\$ 288,817$, while the two are just about head-to-head concerning (post-tax) return on sales (ROS), at 21.2 per cent. Google's business model as an advertising platform is mainly geared towards the Business to Business (B2B) segment, with users both being the target group and generating the content.

Amazon (2020), by comparison, is almost off the scale to the top left: it has by far the highest revenue ( $\$ 280.5$ billion) and number of employees $(840,000)$, yet its profit per employee $(\$ 13,798)$ and ROS $(4.1$ per cent) are the lowest. It is probably widely understood that this is not because the wages Amazon pays are ruinously high. What is more relevant, it appears, is that the company only generates 24 per cent of its revenue from purely data-based activities. Figures pertaining to specific revenue shares for the company's various business fields (see ibid.:38) are only sparsely disclosed. Amazon generally divides its business activities into Product Sales (revenue share: 57 per cent) and Service Sales (43 per cent); moreover, according to the business report, the cloud service AWS generates $\$ 35$ billion, or 12.5 per cent of annual revenue (see ibid.: 68). Likewise, the question of whether $\mathrm{B} 2 \mathrm{C}$ and/ or $\mathrm{B} 2 \mathrm{~B}$ is (more) dominant is also somewhat more complex. We will shortly return to Amazon in more detail (Chapter 8.2), but enough pure numbers for now.

Facebook (2020a) generates almost all (98 per cent) of its revenue from databased activities. At $\$ 70.7$ billion total revenue, it is the smallest among the GAFAM corporations. Facebook shows its strength elsewhere: each of the 44,942 employees generates some $\$ 411,419$ per capita profit-the highest figure among the five Silicon Valley tech giants. ${ }^{5}$ Similarly, despite being the smallest of these corporations, Facebook ranks second for ROS (26.2 per cent). As is the case with Google, its service is mainly oriented towards $\mathrm{B} 2 \mathrm{C}$, whereas the turnover in advertising revenues is clearly a $\mathrm{B} 2 \mathrm{~B}$ market.

Apple (2019) - with the highest net earnings ( $\$ 53$ billion) and second-highest revenue ( $\$ 260.2$ billion) -is the only one of the five GAFAM corporations to report that hardware accounts for a substantial share of its sales (91 per cent). ${ }^{6}$ Thanks to outsourcing and contract manufacturing, however, very few of the 137,000

5 The business consulting firm Deloitte (2015) seeks to illustrate, based on the example of Facebook, that it is insufficient to consider platforms merely with respect to their own revenues and own staff numbers. This "narrow impact", Deloitte explains, is usually markedly smaller than the "broad economic impact" which platforms help create for other businesses. According to this rather generous calculation, Facebook provided more than $\$ 51$ billion in total revenues for third-party companies and secured or created 783,000 jobs in the 28 member countries of the EU in 2014 (ibid.: 3). Apart from platform and connectivity effects, the impact was the most pronounced in the area of marketing, accounting for $\$ 27.7$ billion and 338,000 jobs (ibid.: 7 ).

6 Likewise, Amazon (e.g. Echo, Kindle), Google (Google Home, Google Phone, Google Nest, Pixel Slate etc.) and Microsoft (Surface laptop, Xbox) also generate revenues through their own hard- 
employees actually work in the production of this hardware. Despite the still strongly material base of its business model, Apple reports the second highest profit per employee $(\$ 403,358)$ and ranks third for ROS (21 per cent).

This leaves Microsoft (2019): although the company may enjoy the least 'hip' image among the Big Five and ranks next to last for revenue ( $\$ 125.8$ billion), above only Facebook, a different picture emerges when we consider how much of this revenue is held onto: a total of 144,000 employees generate net earnings of $\$ 39.2$ billion. Microsoft thus ranks third for profit per employee, at $\$ 272,500$, and leaves the rest of the GAFAM companies far behind with regard to ROS, at 31.2 per cent. The strategy of creating technological dependencies over decades, coupled with licence fees, seems to have paid off. Around 90 per cent of revenue accrues from purely data-driven business activities, while a large proportion of the business model is likely oriented towards B2B markets. ${ }^{7}$

In the chart, we can also see the figures for SAP, the only globally important software company from Germany, and for Volkswagen and Tesla, as examples of traditional and disruptive material production, respectively. The different dimensions of these companies aside, the following observations are intriguing:

SAP (2020) shows the lowest revenue of all the enterprises considered here, at $\$ 14.5$ billion, while its number of employees $(100,330)$ is more than double that of the smallest of the GAFAM corporations (Facebook). With net earnings per employee of $\$ 11,861$, the software company belongs to the second tier, ranked even behind Amazon. Given that its target group (B2B) and a central element of its business model (business software and licences) resemble those of Microsoft, the difference in ROS is particularly striking here: at 8.2 per cent, SAP manages to hold onto less than a third of Microsoft's 31.2 per cent. ${ }^{8}$ Microsoft, however, does have a second target group (B2C).

ware, but it accounts for a negligible share of total sales and is thus mostly not even separately declared in the reports.

7 Microsoft (2019) divides its segments into Productivity and Business Processes (33 per cent), Intelligent Cloud (31 per cent; including, among other things, CitHub) and More Personal Computing (36 per cent; including, for example, Windows licences, devices such as the Surface tablet, or computer equipment) as well as Caming (Xbox hardware, games etc.; see 4-5). Incidentally, the purely hardware-related sales cannot be accurately ascertained based on the annual business report. Although the report indicates that some $\$ 6.1$ billion (and thus 4.8 per cent of total revenues) (see ibid.: 89) are generated via 'devices', the item 'gaming' also entails unspecified revenues related to the Xbox as a device, while the item 'Server Products und Cloud Services' also contains an unknown share of total revenue for server hardware. In both cases, the share is likely to be below five per cent; we thus assume another aggregate 5 per cent, which increases hardware's share of total revenue to about 10 per cent.

8 As mentioned before, what is compared here are net earnings, which may explain part of the difference; on this issue, see also the more elaborate reflections (Chapter 2.4) based on a study of the tax-avoidance schemes pursued by Google and other business enterprises (see Tørsl $\varnothing v$ et al. 
Moreover, looking at the relative figures (net earnings per employee and ROS), it is interesting that Amazon, Volkswagen ( $\$ 18,623 ; 5.6$ per cent) and Tesla ( $\$-17,932$; -3.5 per cent) are grouped together the closest and rank markedly below GAFAM. All three are oriented mainly towards $\mathrm{B} 2 \mathrm{C}$ markets and are active in the production or the warehousing and transport of physical objects.

As the differing KPI of the largely data-driven companies already indicate, however, it is not simply a matter of material on one side, and data on the other, so to speak. In the following step, we will consider these corporations more analytically from the distributive-force perspective. Before we do so, however, a brief digression is needed, as many aspects related to the platform economy cannot be fully understood without taking into consideration two central preconditions for the market expansion it aims for.

\subsection{Catalysts for value realisation}

"The enormous expansive force of modern industry, compared with which that of gases is mere child's play, appears to us now as a necessity for expansion, both qualitative and quantitative, that laughs at all resistance. Such resistance is offered by consumption, by sales, by the markets for the products of modern industry." (Engels 1987: 262) We have already dealt with this rather fundamental problem that time after time causes crises (see Chapter 5). On average, the volume of goods produced is always greater than that which can be consumed. That is what necessitates permanent market expansion, which ultimately founders on engendering the equally necessary expansion of consumption. Friedrich Engels' gas metaphor directs our attention to two catalysts for value realisation that have taken on a new quality under current capitalism and cannot be separated from the business models and technologies of digitalisation: infinite investment and ubiquitous consumption. In combination, they promise unbridled market expansion, the overcoming of the consumption cap and thus-if perhaps not the end of the system's susceptibility to crisis - at least a minimised risk. But whether (and when, and for whom) this promise can be fulfilled is another question.

Elsewhere (see Chapter 2.4)-namely in our discussion of Betancourt-I emphasised that venture capital investments are not comparable to investments in stocks. It is not only earnings that are being promised, but market expansion and a permanently exclusive market (overlapping but not identical with the plat-

2018). And this is not just the result of tax loopholes, but also of the respective national legislation, which in the US particularly benefits the super-rich: tax liabilities of American billionaires, measured in per cent of their total wealth, declined by 79 per cent between 1980 and 2018 (Collins et al. 2020: 9). 
form economy). In that same chapter, I argued that over-rated stocks and the sheer masses of venture capital feed on two sources:

Firstly, inconceivable amounts of idle capital, literally 'left over', are neededthat is, after the (mostly extremely optimised and thus very low) tax has been paid, all reasonable classic investments in one's own company have been made and one's private luxury consumption needs have been satisfied. ${ }^{9}$ Ultimately, it all stems from a cycle of value generation and achieved value realisation that has been ongoing for a very long time, in combination with the appropriation and constant accumulation of surplus value in the hands of only a small number of people.

Secondly-as it were, the flipside of this successful cycle-value realisation must have become more important than value generation. This considerably increases the willingness to invest whenever the investment's main promises pertain to the three motives of the distributive forces: when there is a prospect of successful and lasting market expansion (see Chapter 5.1); when the objective is a novel or particularly promising form of stimulating consumers' willingness to consume, combined with-as far as possible-permanent incitement of usevalue appropriation (see Chapter 5.2); and when the investment promises further scaling of the first two motives in the long term and thus offers a chance of outwitting the system's natural tendency toward crisis, at least in the individual investment environment (and even if only for one's remaining life span; see Chapter 5.3).

We have already argued (see Chapter 3.1), proceeding from Mazzucato (2015), that risk investment has little to do with actual risk (and why this is so). We have seen (see Chapter 4.2) how venture capital has long been flanked by discourses of legitimation surrounding disruption and deregulation (Barbrook/Cameron 1996; Murnane 2018), while its weight is increasingly reflected in institutionalised relations between tech companies and venture capital firms (Rothstein 2020). There is no need to repeat all this here. Yet, ever since the bursting of the so-called dotcom bubble in the context of the New Economy (how antiquated that term sounds today!), we all realise that excess capital in large quantities on one side and seemingly guaranteed value realisation on the other must ultimately lead to investment bubbles (the risks of which, in the case of the bubble bursting, are usually then borne largely by those who have neither contributed to the emergence of these bubbles nor benefited from them).

In public and political perception, start-ups and the concomitant investment are largely still associated with the idea of ground-breaking technological inno-

9 Even voices from within economics lament the 'almost religious fervour' with which businesses still pursue the goal of a more efficient use of capital, which has by now become a veritable "capitalist's dilemma" (Christensen/Bever 2014); according to the authors, most investors and executives continue to "think of capital as their scarcest resource" (ibid.: 5) - but the opposite is true: "We are awash in capital" (ibid.: 6). 
vations, although this is in fact rarely the case. Many start-ups launch business models that are already being pursued by others, with only minor nuances distinguishing them from their competitors. And, indeed, often there is nothing technologically new about them either: yes, they all rely on the Internet; yes, they all concern data-based business models and, yes, they are increasingly also about the use of Artificial Intelligence (or so goes the claim).

Joseph A. Schumpeter's notion that only what is realised on the market constitutes innovation (and technologically novel inventions remain irrelevant in the absence of such market success), assigns the entrepreneur precisely this role: not to be inventive themselves, but to be "exploiting an invention" (2003: 133) owing to others and creating markets for (or through) them. ${ }^{10}$ But the difference, firstly, between the narrative and the economic reality and, secondly, between the distinct corporations considered here, lies in how loud, exaggerated or realistic the promises of market expansion are. For there is nothing that indicates any more clearly just how high the expectation of a promised market expansion is than the unbelievable sums of venture capital that flow into digital business models, particularly in the United States. Venture capital is often regarded as the "Holy Grail of Scale" (Gavet 2020: 67), while the major investment firms are correspondingly referred to as "Monsters of Scale" (ibid.: 7).

In 2019 alone, firms in the US digital economy raised almost $\$ 51$ billion in venture capital (NVCA 2020: 20). Although this capital came from 272 funds and 7,960 active investors, a strong concentration can nevertheless be identified here, too: some 28 per cent of total invested capital in 2019 came from the eight largest investment funds (see ibid.: 13). A complex network analysis (see Ferrary/ Granovetter 2009) provides evidence that Silicon Valley's venture capital firms also assume other functions besides funding start-ups. For example, they select the most promising projects and thereby signal to other investors where the best investment opportunities are. According to Maëlle Gavet, who has herself worked

10 Investments into the inventions side of things also seem to be going out of fashion. One study, however, points out what we may call 'the tendency of the rate of ideas to fall': empirically speaking, there is a quite clearly discernible trend towards increasing research efforts, on the one hand, and declining research productivity, on the other (see Bloom et al. 2017). This is illustrated by the example of Moore's Law: today, the number of labour forces required in research to achieve the famous doubling of the component density of computer chips every two years is more than 18 times what it was during the early 1970s. The study concludes that it is becoming increasingly difficult to come up with the right ideas and, more importantly, achieve the exponential growth these ideas are supposed to advance. Others claim that "[c]apitalists seem uninterested in capitalism" - at least in the sense of "supporting the development of market-creating innovations." (Christensen/Bever 2014: 8), emphasising that the operational focus in well established companies has far too long been placed exclusively on performance and efficiency increases, and far too little on market-creating innovations (ibid.: 6-7). 
in the venture capital scene for many years, business culture is imbued with the hunt for "hyper growth", by which she refers to a growth rate of 40 per cent on average for at least one year (see 2020: 70). But it is the industry's "dirty secret", the author explains, that business valuation is usually arbitrary and has more to do with price dynamics than with real value (see ibid.: 71). Evgeny Morozov (2017) highlights an aspect that, in his view, most investors are not even aware of: namely, that the ultimate aim of many start-ups' business model is to eventually be bought out by one of the large tech corporations. In this case, they are not about profitability, but about configuring their business model in a way that makes it compatible with the expansion strategies of Google or Facebook.

In the context of the dot-com bubble, the German sociologist Stefan Kühl developed his concept of Exit Capitalism (Kühl 2005, 2003). Here, he contends that business enterprises have always pursued strategies of tapping other funding sources - such as public subsidies or the capital market-in the absence of operating profit. The aim is merely to maintain solvency (see 2005: 168). According to Kühl, profit thus represents a myth of organisational sociology. One provocative assertion of his analysis - namely that of "Profit as Myth" (ibid.: 147)—could suggest that his argument denies the significance of value realisation and profit. But far from it: Kühl regards the risk-capital firms merely as other actors that enter the game, who are bent on market expansion and profit. After all, start-ups seeking investors are often forced to follow a 'growth model' as soon as they receive their first funding. A start-up "reporting profits, according the logic of the venture capitalist, can be a negative sign" (ibid.: 76). So, profit is anything but obsolete, and nor is market expansion: investment in companies that can potentially achieve large-scale success on certain commodity markets does, by all means, remain a strategic goal. Should this turn out favourable, the start-up and its investors can draw profit from the market activities and continue this market expansion and value realisation for a longer period of time; if not, this is not a problem, at least not for the initial investors, as their profit is secured by a strategically selected exit date.

In this case, the objective is not the start-up's market success: the start-up itself becomes the product. Stefan Kühl's argument could also be reversed: because market success and market expansion have become unreliable options, all other sources are developed (yet the striving for solvency, which Kühl sees as the underlying motivation, cannot alone account for the complexity of the venture capital game). At the end of his analysis of actors, dynamics and processes-which largely remains valid today-Kühl emphasises that the term "exit capitalism" applies only to this kind of investments and is no "megatrend" to describe "the entire economy or even society as a whole" (ibid.: 55). This is accurate: while venture capital investors and their strategies do influence the world of start-ups, the crucial underlying dimensions can be found elsewhere: 
Firstly, (individual or institutional) investors are able to deploy millions and even billions, which they (or their ancestors) were able to successfully extract from the endless cycle of value generation and value realisation. The explosion of the total amount of money and purely speculative earnings aside: at some point, someone produced values that were then realised on markets, which makes such investments possible in the first place. Given that the financial economy and the real economy are increasingly drifting apart, the proportion of such values may become smaller, and the points of contact less direct and less visible-while the bubble grows and grows. Still, the original establishment of the entire speculation game and its persistence in the long run was and is only possible because somewhere, someone was and is generating and realising values.

Secondly, because such staggering investment sums are being channelled into start-ups, some of these start-ups are able to orchestrate market expansion (without even turning a profit), effectively restricting the market expansion (or at least market consolidation) of the dominant corporations. ${ }^{11}$ This severely impedes the value generation and value realisation of the affected companies (which is, of course, the stated goal of frequently invoked 'disruption') and further increases the susceptibility to crisis of the system as a whole-even, or rather, particularly if these start-ups ultimately go bankrupt and the investment was worthwhile only for a small number of investors with a successful exit strategy.

Thirdly, ever since Stefan Kühl's analyses, one thing has become increasingly clear: the venture-capital game has long become a business model that itself increasingly requires more and more distributive forces.

As a glance at the dynamics of risk capital has shown, even when vast quantities of capital are 'left over', it appears to take rather convincing arguments-or rather, promises - to attract backing for one horse rather than another (or: to pick out the one supposed unicorn among the many horses). This requires, on the one hand, the distributive force control and prediction for managing the permanent analysis of all newly emerging start-ups, the assessment of investment risks, and the calculation of the perfect exit point-seeing as all of this, of course, must be surveyed, calculated and forecast. On the other hand, advertising and marketing are also essential, because the start-up (or, in other words: the 'product' called a

11 Those benefiting the most from the venture capital-driven exit and market-expansion strategies are businesses specialising in the distributive force advertising and marketing: according to an analysis conducted by the market research firm Nielsen on behalf of the journal Capital, the battle between the delivery services Lieferando, Lieferheld and Pizza.de over the German market between 2010 and 2019 alone cost more than $€ 780$ million in advertising (see Wirminghaus 2020), with some $€ 175$ million just for 2018. It was no coincidence, then, that in 2019 , Deliveroo withdrew from the German market and Delivery Hero sold its brands Lieferheld, Pizza.de and Foodora to the Takeaway Group, which in turn integrated them into their subsidiary Lieferando; as a result, Lieferando now essentially rules the market without competition. 
business enterprise) must be sold to investors, as the hosts of start-up companies compete not only for these streams of capital, but also for attention, and because the start-up and the investor will only form a partnership if the right promises are made by one side and the other side sufficiently believes in them. Both require very particular and sophisticated distributive forces, including specifically skilled labour forces. That is why Silicon Valley has long developed an entire eco-system of consulting, data-analytics and marketing firms. Needless to say, there are already apps that are challenging the institutional risk investors and seek to make an exit possible through a simple click, without charging expensive fees. For example, the platform Microacquire (2020) promises start-ups (interestingly, only those with an Saas business model-i.e. those with already built-in ubiquitous consumption) an exit within 30 days and to connect them with individual potential investors. More than $15 \mathrm{KPI}$ on the start-ups that are up for sale are offered as a basis for an investment decision, including, in particular, Customer Acquisition Cost, Customer Life Time Value and the number of customers. The promise of market expansion literally becomes the object of marketing itself.

However, the seemingly infinite investment of risk capital can only act as a catalyst for market expansion in the long run if the immanent hitherto-existing barrier to this expansion is (or, at least, is promised to be) dealt with at the same time. After all, as we have already discussed earlier (see Chapter 5): market expansion is systematically linked to risk, and ultimately inevitably represents a crisis-prone process in the long term: according to Engels, "[i]n every crisis, society is suffocated beneath the weight of its own productive forces and products, which it cannot use, and stands helpless face to face with the absurd contradiction that the producers have nothing to consume, because consumers are wanting." (Engels 1987: 269) Surely, today's risk investors must have noticed by now what Friedrich Engels already so accurately described during the last third of the $19^{\text {th }}$ century. And they have. The clue is in the name: the aim of any risk investment is to minimise, through particularly prudent and ingenious analytical strategies, the risk, at least for one's own capital, that exists for any capital and thereby generate exceptionally high profit. After all, one's own successful containment of risk necessarily increases the risk of other, less successful start-ups and investors. Raising large amounts of risk capital from investors therefore always also requires convincing promises regarding consumption. Today, there are even more (digitally based) mechanisms that come into play than we have so far considered at the level of the distributive force advertising and marketing (see Chapter 5.2).

This brings us to the second catalyst for market expansion: ubiquitous consumption. Ubiquitous is to be understood here in its conventional sense, i.e. as synonymous with pervasive, omnipresent or inevitable. Pervasive and omnipresent signal the theological origin of the word ubiquity. That would appear quite appropriate, as we are dealing with forms of consumption whose protagonists like 
to refer to themselves as 'evangelists' and whose products and communities display many of the features of a cult or a sect. Besides that, the act of consumption as an expression of the conscious decision of rational beings falls by the wayside. It is increasingly repeated automatically, ever less as a conscious act, always only a click or voice command away. 'Inevitable' also seems appropriate, seeing as we are dealing with forms of consumption that essentially, through deceptive methods, compel us to consume, or even addict us to consumption. Yet, just as with the gas in the Engels quote, this may also mean: not noticeably so. In biology, animal or plant species that are not tied to any specific habitat are referred to as ubiquists-likewise a fitting term in the context of forms of consumption that have not only long-since shifted from the physical shop to the virtual online version, but that accompany us through our everyday lives on our wrists or seek to fulfil our every wish in our smart home. And, finally, it ties in with the old idea of Ubiquitous Computing (for the first publication on this concept, see Weiser 1991), as these forms of consumption would be difficult to conceive today had it not been for this already articulated idea of an alternative digitalisation.

Market expansion as such represents but a promise to other companies (to investors and to production capital as Amazon's customers). This B2B perspective, however, is inevitably linked to the $\mathrm{B} 2 \mathrm{C}$ level. For the ' $\mathrm{C}$ ' in $\mathrm{B} 2 \mathrm{C}$ has only one function: to consume, i.e. consummate the act of value realisation-the purchase. There is no question that the distributive forces advertising and marketing and control and prediction largely aim at just that: to stimulate the will to consume, predict this will as specifically as possible, most accurately attend to it and, if possible, do so more quickly and better than the competition. The motives are old ones, but the means have been refined and perfected throughout the development of the distributive forces. Amazon succeeds in increasingly coupling this with the third distributive force transport and warehousing - and thereby further shortening the time between the consumption need articulated through the online purchase and its subsequent satisfaction, including through material products. This allows it to ensure value realisation even more reliably (seeing as the promptness of beingable-to-have is stylised as a value in itself by its own advertising and marketing).

One novelty, however, which appears under capitalism only as a result of digitalisation, is the coupling of purchase and consumption. While, in the past, a purchase was commonly made in a shop, in separate instances at certain times, with the actual consumption (i.e. the active appropriation of the purchased use value) being deferred or delayed, occurring in various stages or all at once or not at all, this gap is now minimised. A new dimension of value realisation is opened up: here, a new quality of market expansion emerges-yet the market expands not because the product is digital and the transaction costs are declining, but because the use itself, the act of consumption, can become the product-from the one-off buying act to the sustained and technologically compelling, repeated payment for being 
granted user rights and platform access. The exploitation of labour is complemented by the exploitation of consumption. ${ }^{12}$ And the non-ownership of the means of production (and means of distribution) is complemented by the dispossession of purchased goods. I may think that I have bought the movie on a streaming platform or the e-book on my tablet, yet neither of them belong to me. I cannot pass them on to someone as a gift, leave them to be inherited or sell them on, as I would be able to do with the corresponding physical DVD or a book made of paper and cardboard. I cannot even be sure that I have acquired the use rights for the rest of my own lifetime. The purchased e-book may well disappear from my tablet or the respective app at any time, should the contract between the e-book supplier and the publisher change.

This immediately reminds us of the concept of 'accumulation by dispossession' put forward by David Harvey (see Harvey 2006a, 2003; Chapter 4, particularly: 154, 162-163 and 169-172). ${ }^{13}$ This mechanism includes, among other things, the privatisation of land and communal property; the conversion of collective or public ownership rights into private ones; the suppression of alternative forms of production and consumption; financialisation (redistribution through the deregulation of the financial system); and globally orchestrated manipulations of crises with the aim of wealth redistribution from poor countries to rich ones, as well as government redistribution from bottom to top (via tax and economic policies, but also via the depression of wages in the social and public sectors). And, with a view to new and digitally enabled types of (dispossessive) consumption, we could add: the conversion of ownership forms into a long-term fee-based use permit; the refusal to grant ownership rights; and the user's loss of the freedom to control the consumer article's location, use, modification or maintenance and of the right to pass on the ownership of an item.

12 Klaus Dörre (2017) has more recently made the case for a revitalisation of the concept of exploitation in sociology. Proceeding from and engaging with Karl Marx's concept of exploitation and François Dubet's conception of "injustice at work" (2016), Dörre proposes a research heuristic that distinguishes between "[...] exploiters (appropriating entities such as private enterprises, financial market actors, the government, etc.), their profit (surplus labour within a range of differing labour capacities), heterogeneous groups of exploited (members of the core workforce, i.e. employees with a permanent contract in different segments of the labour market, precarious workers, the unemployed, etc.) as well as the institutional form of the respective class of tests of worth (degree of institutionalisation, regimes of legitimation) [...]" (ibid.: 188-189, translation amended).

13 David Harvey considers these to be new forms of Marxian so-called primitive accumulation-i.e. an accumulation of capital that results not from the generated and realised surplus value created within the capitalist mode of production, but from other sources such as robbery. Given the term 'primitive', it has often been asserted that the concept denotes a phenomenon that capitalism has overcome historically, and yet, the concept has enjoyed renewed interest in more recent years (for a critical discussion of this question, see Bin 2018). 
Here, we encounter what is really new: the real change is not in the control of access to markets (market access is always regulated in some way or another), but in the form of the proprietor's ownership throughout the use of the product. When someone buys an e-book from Amazon, this latter remains the proprietor, just as the publisher remains the proprietor of the book if one were to purchase the same book from the actual publisher as a PDF subject to the corresponding DRM. Besides, exploitation by consumption does not affect only the online gaming enthusiast or the e-pub reader interested in historical novels-not only those who own only their labour power but no means of production. For it likewise affects the mid-tier entrepreneur whose business uses office software from Microsoft-although the term exploitation may seem slightly out of place here and is, in fact, not entirely economically accurate. Ultimately, it is something else that we are dealing with: the possibility of value realisation without a change of ownership. And this can lead to very different power asymmetries between companies, too.

Platforms only provide access and, as is the case in any market, set the rules. Digitalisation simplifies this access and makes it more easily controllable. Incidentally, the principle of not actually owning the purchased good-in the sense of a free disposal thereof-can also take effect in the form of legal regulations and may well concern non-digital products, too. This is the case, for example, when the manufacturer's warranty for the car I have bought (or company-owned commercial vehicle) becomes null and void if repairs are done by a non-licensed garage (or, say, by the company's own technician). Or, if farmers in both India and Indiana are forbidden to take seeds from the plants they themselves have grown from purchased seed and put them back in the soil. The legal (and, to some extent, biotechnological) base of the corresponding business models is the obligation upon the seed buyer to exclusively use the brand-owned pesticides with the purchased genetically modified seeds. In this context, the benefits of digitalisation are multiple: it makes it easier to monitor legally compliant use; it reduces the costs of constantly repeated value realisation; and it makes It possible, via the Internet of Things, to extend this accumulation mechanism to ever-more (including physical and low-cost) products. Yet, from the capital perspective, all these aspects constitute optimisations. The driver, or source of this accumulation lies elsewhere.

Another aspect-related to the already discussed unpaid labour in surveillance capitalism (see Zuboff 2019) - is more closely linked to consumption than is apparent on first sight. It indicates mechanisms and strategies that may be most obvious in the area of social media but which can also be found in online gaming as well as in the previously mentioned third-party tracking. This characteristic will increasingly encompass all new forms of digitally enabled consumption: inevitably, the use of purchased products (say, an Amazon Echo) or of platforms (i.e. during free-of-charge consumption) simultaneously generates unpaid labour for the real owner of the product used (in the best case serving the improvement of 
the service and/or product and, most likely, fostering the emergence of ever-new business models surrounding the productive force advertising and marketing). The corresponding implications for informational self-determination in $\mathrm{B} 2 \mathrm{C}$ as well as for corporate (informational) sovereignty in B2B are not even foreseeable this point. In this sense, too, consumption becomes ubiquitous, for what used to be separated-consumption as a purchase act, consumption as the appropriation of use value, and surplus value-generating labour for others-can now occur simultaneously. Examining the full range of the new forms of consumption made possible by digitalisation would certainly fill another book. Hence, I will limit myself to one central aspect here: addiction as a method.

The US docudrama The Social Dilemma (Orlowski 2020), released in 2020, critically addresses the effects of social media, blending the dramatic plot of a play-like rendering with interviews with industry insiders such as Tristan Harris (formerly of Google), Tim Kendall (formerly of Pinterest) and Justin Rosenstein (inventor of Facebook's 'Like' buttons) and critics from other areas such as sociologist Shoshana Zuboff or legal scholar Rashida Richardson (AI Now Institute etc.). The film alleges the intentional fostering of addiction-like behaviour in order to keep people on the respective websites for as long as possible. This is most trenchantly illustrated by the question raised in the film of which industries call their customers 'users' - the answer being, drug trafficking and social media.

This phrase was probably originally taken from a blog post with a slightly different wording: "Drug Dealers and IT are the only people who call their customers 'users'." (O'Leary 2012) This witty remark aside, there is reliable evidence of parallels between these two (respectively, illegal and legal) economies, though they relate less to the motive of getting people addicted than to structural similarities between the industries. They were identified by Tom Wainwright (2016) in his comparative analysis of the operations and the economics of the value chains of Walmart and Colombian cocaine cartels (see ibid.: 9-28) and of the franchise strategies of Mexican cartels and McDonald's (see ibid.: 133-148).

A few weeks after the release of The Social Dilemma, Facebook (2020b) felt compelled to release a reply denying any deliberate encouragement of addictive use of social media: generally, Facebook stated, the film fails to offer a nuanced representation of the technology, instead unjustly blaming social media platforms for complex social problems. Above all, and presented as the first of the seven counter-arguments, the corporation emphasises: "Facebook builds its products to create value, not to be addictive." (That is to say, value instead of addiction; ibid.: 1) However, this is precisely to miss the film's central criticism, as it seeks to show just the opposite, namely that the strategic encouragement of addictive behaviour is what creates value (i.e. value through addiction). Facebook then lists several examples to illustrate that it has no interest in prolonging periods of use-the objective being "[to] offer value to people, not just drive usage" (ibid.). Yet this is not a convinc- 
ing counter-argument either, for no one has suggested that the motive for longer use periods is simply to achieve a longer duration of use alone. But for a company that makes its money from ad revenues, the duration of use translates into cashwhich was already the case with old-fashioned TV advertising. And if a company is able to offer more custom-tailored and target group-oriented (and thus more expensive) advertising to its clients based on the analysis of user behaviour, it will also have a considerable interest in people using its own social media platform for as long and as comprehensively as possible.

One need not immediately associate this with pathological addiction, but the methods used for this kind of marketing do exhibit certain parallels. Yet, both the film, which, of course, presents the issue in a somewhat pointed tone, and Facebook's counter-arguments aside: there is much evidence that the allegation of strategies to get users addicted, proliferating across the entire industry, is based on very real and serious facts. The origin of such strategies can be found in the "Player Centric Design" (Schüll 2012: 52-75), which was already used in the design of slot machines in Las Vegas to increase the "continuous gaming productivity" (ibid.: 52; emphasis in the original) of individual gamblers. In this context, productivity is not measured by the results of performed labour, but by the extent of success in "accelerating play, extending its duration, and increasing the total amount spent" (ibid.; emphasis in the original). This can be transferred not only to the use of social media (more frequent clicks, longer website viewing periods, thus generating more ad revenues), but also to online shopping (adding items to the shopping cart more frequently, and longer website viewing periods, thus increasing the total amount spent). The author describes the intentional and strategic pursuit of Addiction by Design, including through the architecture and atmosphere in gambling halls, and the specific appeal made to the emotions (see ibid.: $35-51$ ). This logic applies just as much to our present, when we consider Customer Journey, UX Design and click baiting. Besides, the precursors of tracking and user-behaviour prediction have also been around for some time: gamblers in a casino in Atlantic City were already being tracked through the use of punch cards as early as 1985, RFID came into use from the year 2000 , and, ever since 2007 , the industry has been working on methods to analyse the behaviour-related data stored in the slot machines (see ibid.: 137-165).

Ultimately, the gambling hall is designed to encourage addictive behaviour. The same objectives guide what Adam Alter refers to as Addictive Technology (2018). Although this is not to be equated with a physical addiction to substances, it is certainly more than a mere analogy or metaphor, too. Behavioural addiction can in fact be empirically measured: after injecting a dose of heroin, the neurons in the brain of an addict flash up in similar patterns as those in the brain of a gambling addict when starting a new quest in World of Warcraft (see ibid.: 71). 
Some years ago, Nir Eyal's book Hooked (2014) described just how intentionally 'habit forming products' are created on the basis of ever-greater amounts of user data. An external or internal trigger initiates a certain action in anticipation of a reward. This behaviour is then rewarded in varying forms-though it is precisely the unpredictability of the type of reward that prompts the desirewhich prepares the ground for the user to invest (time, data, effort, social capital or money) in the product (see ibid.: 6-14). ${ }^{14}$ From our perspective, this can mean either surplus-value generation (unpaid work) or surplus-value realisation (purchase), depending on the business model. The frightening aspect about this is not only the manipulation of emotions consciously bypassing the rational mind, but the close link to economic objectives. Eyal (see ibid.: 15-24) lists four reasons why this strategy pays off (with the above-cited parallelism between the concept of the 'users' in IT and the drugs trade becoming even more obvious):

Firstly, the so-called Customer Lifetime Value can be increased, i.e. the revenue achieved with a single customer before they cease to use the service (be it because they quit the habit, die, or switch to the competition); secondly, pricing is flexible: you only pay once you have become hooked. For example, many games only charge a fee once a certain level has been reached and the user can no longer imagine spending their free time without playing this game. Business software also banks on this approach: for example, a basic version of a given collaboration software that allows for a small number of users and offers slightly limited functionality represents the equivalent of the gateway drug. Once collaborative everyday work processes are no longer conceivable without this software, a company's need to expand its use to other teams or activate additional functions considerably increases its readiness to pay; thirdly, Viral Cycle Time, i.e. the time it takes a user to invite another person, can be shortened. This saves advertising efforts and facilitates faster scaling of the business model. Fourthly, the competitive advantage, once achieved, can be maintained: the risk of a user moving to the competition decreases even if the competitor offers lower prices or better products, because changing one's habits is perceived as too great an effort.

Proceeding from insights from neuroscience, neuromarketing distinguishes between three different brains: "The new brain thinks. It processes rational date. The middle brain feels. It processes emotions and gut feelings. The old brain decides. It takes into account the input from the other two brains, but the old brain is the actual trigger of decision." (Renvoise 2008: 6) This just about defines the target dimensions. Neuromarketing-just like the approaches in the digital world described above-aims at the unconscious and (explicitly) not at reason and

14 Adam Alter (2018: 93-236) suggests a slightly more differentiated process, though it is essentially based on the same motivations: goals, feedback, progress-escalation_cliffhanger(s) — social interaction. 
rationality. And, as outdated and, considering the Enlightenment, pre-modern (if not prehistoric) as this may sound, it is perfectly compatible with a highly individualised society. For, according to the author, the old brain not only reacts very strongly to simple opposites - to inputs which can be literally grasped, to sensory stimuli, obsessing with the beginning and the end instead of concerning itself with the in-between, and loving emotion-but it is also and primarily "self-centred", i.e. it revolves around itself and is fully immersed in satisfying its own needs (see ibid.: 11-18).

Seeing as such stimuli do appeal to what is sometimes called our saurian brain - our primitive ego-the fear of being subjected to imperceptible and uncontrollable manipulation is as justified as the attempts to refute such an assertion are promptly made. For example, the popular-science volume Neuromarketing for Dummies emphasises right at the beginning that neuromarketing is not out to manipulate us all into buying things we do not need. This task is attributed to marketing: "Marketing is a field devoted to influencing people to like things, and ultimately buy things, including things they may not need." (Genco 2013: 8) Neuromarketing, by contrast, the author claims, is simply the concomitant method of measurement, simply "a new way to measure whether and how marketing is working" (ibid.; emphasis in the original). What is obviously intended to assuage us can only fail, for logical reasons alone: if $\mathrm{X}$ is intended to manipulate, and * $\mathrm{X}$ is supposed to help us to understand, through certain measurements, how that manipulation works, then $\mathrm{X}$ will naturally take the findings produced by * $\mathrm{X}$ into consideration when devising any new manipulation techniques.

This is not the place to dwell on self-descriptions, consultants' narratives or the scientific foundations of neuromarketing. Still, the term itself indicates that two very distinct disciplines (and fields of application) are edging their way towards one another, with their overlapping interests referring to 'the neural'. That is, neuroscience, which studies neural processes in the brain through imaging methods; and Deep Learning procedures, which are also referred to as neural (although essentially, they have very little in common with the biological concept of the neural). New business models and the corresponding digital tools are coming into play precisely at this interface, such as those for Emotion Detection via language, voice or facial expression. The associated expectations of market expansion are accordingly euphoric: in the United States alone, these technologies generated total revenues of $\$ 21.6$ billion in 2019, with an expected increase of 24 per cent by 2024 (see Markets and Markets 2020). The providers considered in the market report include-alongside numerous start-ups (also from Europe)-mainly familiar names: there is Google, Apple and Microsoft, from among the GAFAM group, but also those who were already influential in the early days of digital capitalism such as IBM or NEC (see ibid.). 
A recent study predicts a sea change as a result of neuromarketing, which will change the ways in which business works for all actors concerned (see Moses/Clark 2020: 449). According to the authors, neuromarketing developed from a dubious concept to a recognised academic and commercial discipline in just a short period of time, drawing great interest and raising high expectations (see ibid.). From the analytical perspective which we have elaborated here, the most likely, if not only possible interpretation would be: while the distributive forces advertising and marketing as well as control and prediction -in new forms and drawing on scientific advances-are joining forces at the highest level and are becoming increasingly efficacious on the market, in consumption and throughout society (as well as in our minds and hearts), the scholarly engagement with these processes and phenomena is only just beginning (see Mouammine/Azdimousa 2019). The Neuromarketing Science \& Business Association, founded in 2012 , is dedicated to just that, connecting science and businesses in the field of neuromarketing around the world. The association lists more than 90 companies specialising in the field, around 46 per cent of them based in Europe, 24 per cent in South America, 16 per cent in North America and 12 per cent in Asia and Australia (see NMSBA 2020a). Anyone who hopes that this organisation's Code of Ethics might include the protection of end consumers will be disappointed. Rather, the association prioritises three issues in this context: "[...] to restore the confidence of the public in the legitimacy and integrity of neuromarketers; to ensure neuromarketers protect the privacy of research participants; to protect the buyers of neuromarketing services" (see NMSBA 2020b) - that is to say, the task at hand is to win public trust (reassurance), to protect the data of study participants and those businesses (a matter of course, really) that purchase neuromarketing services (why do they, actually?). The target objects - namely all of us, as buyers-do not feature among the association's ethical priorities.

Based on the examples of ubiquitous consumption, our perspective makes it possible to identify the actual economic advantages beyond operational aspects: a maximum value realisation can be secured in the long term, the costs for other forms of the distributive forces advertising and marketing can be minimised, the user's unpaid labour (including in the form of social capital) can be harnessed for both surplus-value generation and market expansion. Besides this, competition-related market risks cannot only be reduced, but be better anticipated and more easily controlled, too. All these advantages shift the efforts aimed at value realisation from the distributive force advertising and marketing to that of control and prediction. What might have been (additionally) spent on advertising in the past is now likely to be swallowed up by the high salaries of expert employees with special knowledge in Machine Learning or neuromarketing. Here, again, it appears that many effects create a real competitive advantage only so long as not all competitors in the business employ the same methods. Nor is there any 
guarantee of infinitely progressing market expansion. Still, our most intimate inner self-our unconscious-has fallen prey to this manipulative encroachment for some time, without, it seems, prompting any political regulatory measures or even any serious consideration thereof. Yet, this is strongly needed, as "the attention merchants" with their "[...] game of harvesting human attention and reselling it to advertisers [...]" (Wu 2017: 6) have not only come to constitute a considerable segment of the US economy (ibid.), but are increasingly determining our life and our future "[...] insofar as that future will be nothing more than the running total of our individual mental states" (ibid.: 352).

The combined effects of the distributive forces and the shifts between them can already be discerned in these examples of ubiquitous consumption. We may safely assume that, in the future, the companies with an edge over the competition will not be the ones who take the lead in specialising in one specific distributive force, but rather those who are able to focus on and service several distributive forces simultaneously and constantly generate different and new bundles of business models. To get an idea of how this may work, we shall now take a closer look at Amazon.

\subsection{The distributive forces and merchant capital 4.0}

The chart (see Fig. 6) illustrates how the GAFAM corporations and crowd platforms as well as the most important current digital technologies (left column) can be classified from the distributive-force perspective. The crucial factor is the actual use value for 'real' customers, i.e. the actual target group of the respective business model. In the case of a manufacturer of collaborative lightweight robots, for instance, this would refer to the companies using them, or in the case of Facebook it would be the companies who pay for advertising on (or via) Facebook (and not the users). This summary overview thus intentionally focuses on the B2B perspective (after having briefly discussed an example of B2B's systematic interlinkage with the $\mathrm{B} 2 \mathrm{C}$ and consumption side in Chapter 8.2). The guiding question underlying this representation is: what specific functions do the services provided by the GAFAM and platform companies - as well as by digital technologies - fulfil for business customers? These functions are broken down into the following columns:

- Functions linked to surplus value generation and the productive forces: do the digital services help the customers become more innovative (i.e. develop entirely new sources of surplus value production)? And/or do they support business customers in reorganising their processes in a way that the (relative or absolute) share of surplus value can be increased? The analytical foundation for this step was set out in Chapter 4. So, just to reiterate what I stated earlier: the 
distributive forces are to be understood as part of the productive forces; we are distinguishing between the two for analytical purposes here (see Chapter 7.3).

- Functions linked to surplus value realisation and the distributive forces: are the business customers of the digital and platform companies being provided with or offered specific services in any of the domains of the distributive forces advertising and marketing, transport and warehousing, or control and prediction (see Chapter 6)?

- Circulation promise: does the combination of distributive forces and specific forms of digitalisation entail exceptional promises of double market expansion and/or permanent value realisation through effectively compulsory consumption (see Chapters 5 and 8.2)?

Fig. 6: Business enterprises and technologies from a distributive-force perspective

\begin{tabular}{|c|c|c|c|c|c|c|c|c|c|}
\hline \multirow{2}{*}{\multicolumn{2}{|c|}{ Business model perspective }} & \multicolumn{3}{|c|}{ Value generation / productive forces } & \multicolumn{3}{|c|}{ Value realisation / distributive forces } & \multicolumn{2}{|c|}{ Circulation promise } \\
\hline & & Innovation & $\begin{array}{c}\text { Absolute } \\
\text { surplus value }\end{array}$ & $\begin{array}{c}\text { Relative } \\
\text { surplus value }\end{array}$ & $\begin{array}{l}\text { Advertising } \\
\text { \& Marketing }\end{array}$ & $\begin{array}{l}\text { Transport \& } \\
\text { Warehousing }\end{array}$ & $\begin{array}{l}\text { Control \& } \\
\text { Prediction }\end{array}$ & $\begin{array}{c}\text { Market } \\
\text { expansion }\end{array}$ & $\begin{array}{l}\text { Ubiquitous } \\
\text { consumption }\end{array}$ \\
\hline \multirow{8}{*}{$\begin{array}{l}\text { Platform } \\
\text { economy }\end{array}$} & Google & & & & & & & & \\
\hline & Amazon & & & & & & & & \\
\hline & Facebook & & & & & & & & \\
\hline & Apple & & & & & & & & \\
\hline & Microsoft & & & & & & & & \\
\hline & CrowdWork & & & & & & & & \\
\hline & CrowdFunding & & & & & & & & \\
\hline & Matching platforms & & & & & & & & \\
\hline \multirow{6}{*}{$\begin{array}{c}\text { Digital } \\
\text { techno- } \\
\text { logies }\end{array}$} & Internet of Things & & & & & & & & \\
\hline & Additive manufacturing & & & & & & & & \\
\hline & Collaborative Robotics & & & & & & & & \\
\hline & Wearables & & & & & & & & \\
\hline & Driverless Transport & & & & & & & & \\
\hline & AI / Machine Learning & & & & & & & & \\
\hline
\end{tabular}

For our purposes, it is necessary to always consider both the buyer and the company perspective. After all, the question from our distributive-force perspective is not: what promises are associated with the current digital technologies? Or: how were the GAFAM corporations able to grow to such proportions on the back of digitalisation? But rather: what specific economic demand is being serviced by the business models that only became possible as a result of digitalisation? And does this help explain their dissimilarity and their varied business success? In the chart, 
the darkness of the grey colour value of a field symbolises the extent to which a company or technology offer the corresponding functions of the productive or distributive forces as a business model-or rather, service-and how closely this is tied to circulation promises. The darker the field, the more this applies.

In this analytical step, we thus intentionally ignore another level, one which nevertheless remains highly relevant in digital capitalism, namely the deployment and development of productive and distributive forces aimed at the optimisation of a company's own surplus-value generation. After all, both the companies providing Industry 4.0 or other digitalisation technologies and, at least in part, the GAFAM corporations represent not only distributive but also productive capital. There are two reasons for omitting this aspect here: firstly, the orientation towards organising one's own processes in a way that the maximum surplus-value generation is achieved again and again is anything but typical of digital capitalism. Secondly, we encounter this orientation as much in the small manufacturing company as in the multinational digital corporation. The methods used and the means and strategies may differ-but the objective is the same. Incidentally, the essence of this was already analysed - both comprehensively and accurately-by Karl Marx. Yet what we are seeking to discern here, from a political-economic perspective, is what is new about digital capitalism. We shall therefore limit ourselves to the services aiming at boosting the value generation and realisation of business customers.

The overview serves only as a rough classification; neither is it entirely based on hard data, nor does it represent a conclusive assessment. In the following deliberations, I will therefore not explain in detail each and every coloured field (nor the ones left blank). My aim here is to present an approximation, to illustrate tendencies. In this sense, the initial overview reveals two aspects: firstly, we generally find more coloured fields in the area of value realisation and distributive forces than in the columns depicting value generation and the productive forces. Secondly, the circulation promises are more explicit in the platform and GAFAM corporations than in the technologies (likely owing to the nature of the matter, respectively). We may note the obvious: the business enterprises and means of production of digital capitalism seem to be clearly oriented towards value realisation.

This is an important insight, not least because the technological facets indicated in the chart can also all be found in the concepts and debates surrounding 'Industry 4.0'. The buzzword 'Industry 4.0' itself- first coined about a decade ago in the context of the Hanover fair in 2011 (see Kagermann et al. 2011)—entails a major circulation promise: it is hoped that additive manufacturing processes and $3 \mathrm{D}$ printing will enable personalised products and thus create new market segments, while the Internet of Things is expected to tie markets and production together more closely and flexibly. Beyond this, there are high expectations-or rather major concerns, at least with a view to the labour market-that Industry 4.0 
will lead to immense productivity increases because, for example, lightweight and collaborative robotics promise automation even in areas that have thus far hardly been automated; because wearables might make it possible to instruct unskilled staff on how to perform complex tasks; or because maintenance intervals can be extended and planned in a more detailed manner if machine and production data have been analysed via AI or Machine Learning. These promises and expectations are also reflected in the chart, even though the outcome in reality often differs considerably, as the aforementioned future scenarios were and are confronted with multiple obstacles (see Pfeiffer 2018b, 2018a, 2016b). But even if we imagine the listed technologies as being closely linked to the shop floor, the functions and promises geared towards value realisation and the market-and thus the technologies' use as distributive forces-clearly take precedence.

Among the technologies listed in the chart, there are two that are almost inseparable from all three distributive forces and both circulation promises, albeit to varying extent: the Internet of Things and AI, or rather, Machine Learning. On the one hand, they promise, both independently and in combination, more targeted production and higher value generation-that is, through an increase in surplus value, just to be precise. More direct and flexible links to the market, which are at the centre of all usage scenarios, make it possible, on the other hand, to organise all three functions of the distributive forces more effectively and partly in combination with one another. All this becomes an expression of circulation promises that are to be realised on a new level. In the process, the other technologies are either left out or integrated into the process of value realisation via the Internet of Things, as suppliers of data (however 'big' these datasets may be), which then becomes both the object and raw material for self-learning systems.

When we consider the companies and types of platforms listed, it is not only apparent that value realisation and the distributive forces take centre stage, as expected, but also that there is a wide range of corresponding business models. Hence, an explanation of the business success and/or the valuation by investors (regardless of whether justified or not) which, as is rather common, simply points to the decreasing marginal costs, to the alleged immateriality of the products or even to the data-represent-the-oil-of-the-21 ${ }^{\text {st }}$-century meme is inadequate (as seen in Chapter 8.1). Only two of the companies have a colour filling across all the fields pertaining to value realisation and circulation promises: Microsoft and Amazon. But only in the case of Amazon are most of the remaining fields also marked dark grey. We will therefore conclude this somewhat cursory interpretation of the overview at this point and, as we had anticipated, dig a little bit deeper in the following section.

Among the GAFAM corporations, Amazon is in various regards a special case (see the comparison of key performance indicators (KPI) in Chapter 8.1). Neither does the company rely entirely on data-driven business nor does it increasingly 
invent or produce its own new hardware, as Apple does, for example. That said, the significance of the physical dimension is still often underestimated in the debate about Amazon - as in the debate about the platform economy more generally. In its business report for 2019, Amazon indicates the costs for the distributive force transport and warehousing at $\$ 37.9$ billion (see Amazon 2020:26) and thus 13.5 per cent of total annual revenue.

Each year from 2011 to 2019, Amazon's logistics costs increased more than its total revenue: in 2011, logistics costs rose by 50.2 per cent compared to the previous year, but total revenue 'only' by 33.7 per cent. It took until 2019 before the trend was reversed: compared to 2018 , logistics costs now increased by 24.6 per cent, total revenue by 27 per cent (see Ti Insights 2020a:3). Although logistics costs were on the rise for other online retailers during this period, too, hardly anyone experienced an increase comparable to Amazon's, let alone for such a prolonged period, and even with a higher Delta than in revenues (see ibid.: 11).

In debates surrounding the platform economy, figures from investment and analytics firms as well as scholars commonly interpret the immense investments Amazon is channelling towards the distributive force transport and warehousing as an expression of a long-term market strategy. And they most likely are that: a circulation promise of unprecedented market expansion, which is objectively verifiable as well as discursively potent. ${ }^{15}$ Unfortunately, the investments and their real effects are rarely critically questioned. For instance, retailers who run classic high street shops tend to have-as opposed to what one may assume-lower logistics costs (relative to total revenue) than those with multiple distribution channels ('omni-channel') or pure online retailers. The mass distribution of palletised goods to unchanging shop locations still proves to be more cost efficient than individual pick-and-pack fulfilment processes and the associated last mile delivery (see Ti Insights 2020a: 1). Although Amazon has acquired a successful US supermarket chain (Whole Foods), this enterprise is active in the foods industry, of all economic sectors, and thus in the business of handling perishable goods. Whether this proves to be an ingenuous strategy of market expansion into completely new territory or just a bad investment remains to be seen.

The exceptionally high investments could also be explained in part (and the emphasis here is on 'also', as one does not exclude the other) by inadequate or (at

15 Amazon represents a special case with regard to market expansion as well. This is usually discussed with a view to the product line, as in: from a bookshop to an online marketplace for just about everything. Yet Amazon also pursues market expansion towards new and, above all, institutional buyer groups: that is to say, alongside business accounts—which have existed for a long time are aimed at the procurement side of businesses-Amazon is increasingly targeting the public sector, seeking to forge cooperation agreements that oblige public authorities and entire municipalities to buy from the company (on this, see the study on the corresponding strategies in the United States by LaVecchia/Mitchell 2018). 
least thus far) unsuccessful automation strategies. By comparison: the annual logistics costs for JD.com, the second major Amazon counterpart in Asia besides Alibaba, have been rising largely in parallel with revenue (see Ti Insights 2020a: 8). The company Ti Insights, which specialises in analytics and consulting in the area of Logistics Service Providers (LSP), regards this as an effect of the low labour costs, but also of consequent automation strategies: for example, JD.com has invested in fully-automated 'dark warehouses', in which just four employees are able to process over 200,000 shipments per day. This is rendered possible by the standardisation of goods-or packages, rather-in terms of their form, size and weight (see ibid.: 9). Amazon itself, however, is not exactly famous for its high wages: its warehousing staff make around 15 per cent less than the same group of workers earn at other companies in the same region (see LaVecchia/Mitchell 2018: 56-58). Above all, however, in introducing collaborative robotics, Amazon (2019) is pursuing a different automation approach, claiming that such robots are already 'harmoniously' collaborating with human workers in 26 of the 175 fulfilment centres worldwide. ${ }^{16}$ Once again, it is currently unclear whether Amazon's automation strategy will triumphantly prevail, or fail. One thing that is clear is that not even the manufacturers of lightweight robotics can confirm any productivity increases resulting from their use (see Pfeiffer 2019b). Based on available data for the year 2015, Ti Insights deduces that Amazon-taking into account its retail and logistics business alone-achieved an operating profit of about 4 per cent or less. It thus fared hardly any better than the leading providers of contract logistics services-despite being backed by much greater capitalisation (see $\mathrm{Ti}$ Insights 2020a: 4).

Besides this, Amazon is increasingly offering its own products for sale (after all, no one has as accurate an insight as Amazon does into what kind of products will definitely sell in large quantities). ${ }^{17}$ However, the business report does

16 Robots would replace certain tasks, not human beings. According to Amazon, human labour would thus become easier and be relieved of unpleasant and tedious tasks (see Amazon 2019). This rather sugar-coated self-description markedly contrasts with an investigative report (see Evans 2020) which demonstrates that the performance requirements and monotonous tasks have increased particularly in those fulfilment centres that Amazon has automated as outlined above. The number of workplace accidents at automated warehouse facilities is especially high: in 2019, some 14,000 Amazon employees suffered injuries so severe that they led to sick leave or limited their ability to work. The company's accident rate is thus twice as high as the industry average, rising by 33 per cent in the automated fulfilment centres between 2016 and 2019 alone (see ibid.).

17 As demonstrated by the widely publicised case of kochmesser.de, Amazon does not hesitate to throw up obstacles to competitors' business models on its own platform, in part drawing on rather dubious methods (see Bütikofer 2015). The extent to which Amazon uses its own financial strength and the knowledge its website generates against providers/sellers on its own platform has become increasingly clear over the past few years: for example, Amazon offers its own 
not specify the proportion of these sales. According to estimates by the German Retail Federation, some 40 per cent of Amazon's online revenues in Germany are generated through the company's own product line (see HDE 2020: 25). Whether or not this applies on a global scale is difficult to ascertain. Germany is Amazon's largest national online market outside the US, accounting for $\$ 22.3$ billion or 7.9 per cent of annual revenue (see Amazon 2020: 68).

Only at closer inspection do we encounter the more intriguing numbers-if, that is, they can be reconstructed from the available data to begin with. The British firm Ti Insights points out that Amazon's cloud service AWS may have generated only 13 per cent of total revenue in 2019 , yet at the same time it accounts for an impressive 63 per cent of the company's net earnings (see Ti Insights 2020b). In their whitepaper, the authors from Ti Insights conclude that Amazon "remains a web-services company with a retailer attached" (ibid.: 1). They find it rather difficult "to disentangle the sales profile of Amazon with a mix of third party, electronic media and Amazon's own physical inventory"; what is certain, they state, is that Amazon's revenue simultaneously drives investments. Correspondingly, in 2019, Amazon saw an increase in the Cost of Sales of 103 per cent compared to the previous year. According to the authors, the objective of these vast investments in warehousing capacity, fulfilment centres and "new in-house, large-scale, technology driven infrastructure" is "to increase the speed of response, itself a part of an attempt to grow closer to the customer and exploit the marketing potential of devices such as Alexa" (Ti Insights 2020b: 2-3). Leaving aside the fact that Alexa is a language assistant and not itself a device-instead requiring a device to run on such as, say, Echo-there could hardly be an indicator more definitive than these figures to show that Amazon is determined to consolidate its leadership position when it comes to combining the most diverse distributive-force strategies.

We could thus assume that the revenues Amazon generates on its shopping platform mostly come from a bundle of services-performed via different and interlocking distributive forces-which Amazon offers to manufacturing enterprises. As it were: distributive-force fulfilment. Correspondingly, one might expect Amazon to advertise the listed products on the platform, to store, package and despatch the products-and charge fees from every company that uses these services. And, indeed, these fees are being charged—though not only after a service has been subscribed to, but even before that:

If, say, a small-scale book publisher manages to sell 1,000 copies of a book at $€ 10$ each, amounting to $€ 13,000$ (including shipping costs of $€ 3$ per copy), then

\footnotetext{
brand products at below market price (see LaVecchia/Mitchell 2016: 15-16), structures seller fees in a way that undermines the innovative capacity of competitors (ibid.: 18-23), favours its own products in search results (ibid.: 24-25), or disadvantages non-Prime members through longer delivery times (ibid.: 29-30).
} 
Amazon charges sales fees of $€ 1,950$ plus another $€ 1,010$ in transaction fees, totalling $€ 2,960$ (according to the Amazon Services fee calculator 2020). Seeing as the publisher hopes to sell more than 40 products per month through this channel, he or she must set up a professional seller account, which costs $€ 39$ per month. Let us optimistically assume that our publisher not only sells all of the 1,000 copies but manages to do so within a single month, meaning that the account fee would only be charged once. ${ }^{18}$

So, in this example, Amazon would be entitled to almost 30 per cent of the sales price (and that is before the seller has even despatched the book, so she or he will still have to pay the postage-which, in reality, is closer to $€ 1.90$ than $€ 3$ ), purchase packaging material, organise handling and despatch etc.). To be sure: these 30 per cent are due not because Amazon advertises, stores, packages and despatches the product (these, so to speak, real distributive efforts could by all means also be delegated to Amazon, but only for an additional fee); rather, our imaginary publisher pays this 30 per cent fee simply to be granted access to distribution. It seems he or she could do with a bit of business coaching. For all of this, as a whole, ultimately does not really pay off, arithmetically speaking. It is worthwhile only if the promised service includes market expansion (and if the bulk of the fees accrues only after a successful sale).

It would appear that Amazon earns most of its income through additional fees that are charged for certain services-which has always been common in retail, only this time these fees are greater, more digital, and more global. So, is there nothing new here? After all, the relevant economic actors who generate their

18 The pricing process is rather complex and confusing. If our book seller were to specialise in expensive illustrated books at sales prices around $€ 100$, the sale of 100 copies would entail a fee of 26 per cent of total sales payable to Amazon, whereas the sale of 1,000 copies would command a fee of only 16.5 per cent. Percentage-based sales fees (which do not apply to small-scale sellers with less than 40 articles sold per month) differ strongly depending on the respective class of goods. They start at 7 per cent (e.g. for tyres, computers or large electronic equipment), are often in the region of 15 per cent (e.g. educational materials, software, sports \& recreation) and can even reach up to 45 per cent (as of April 2020) in the case of accessories for Amazon devices. In most classes of goods, a fee of at least $€ 0.30$ per sold article is payable. This percentage fee applies not only to the price of the article, but also to shipping (and/or gift-wrapping) costs. All these costs accrue if sellers despatch the ordered goods themselves; if Amazon is commissioned to take care of these tasks, additional costs accrue for shipping by Amazon, potentially monthly warehousing fees, or fees for optional multi-channel shipping. Additional fees are also due in the case of very large sales volumes (e.g. 2 million items sold per month). For all media, a fixedrate transaction fee is also due per item sold (for books: $€ 1.01$, for music/DVD/software articles etc.: €૦.81). If someone were to sell drugstore products in the same quantity and at the same price as in the book example, Amazon's share would be lower, but-in the absence of the transaction fee-with a reverse progression: 10.8 per cent fees for sales of 1,000 articles for $€ 10$ each, or 15.8 per cent for the sale of 100 articles for $€ 100$ each. 
profits not through their own production processes but by organising trade on behalf of production capital already existed in Marx's day. According to Karl Marx, this so-called "merchant's capital grows with the progress of the capitalist mode of production, with the ease of entering retail trade, with speculation, and the redundance of released capital." (Marx 1998:310)

Indeed, Marx does assume a merchant who relies on existing funds or those obtained at their own risk in order to purchase goods which can then be sold on the market with a certain surcharge. The merchant's profit is thus determined by the amount of invested capital: "The merchant's profit is not determined by the mass of commodity capital turned over by him, but by the dimensions of the money capital advanced by him to promote this turnover." (ibid.) Merchant capital can thus never achieve a greater profit than industrial capital. Considering the KPI presented earlier, and particularly when compared to the other GAFAM companies, Amazon-the company that corresponds to the concept of merchant capital the most-seems to confirm Marx's assertion. In the same vein-and likewise referencing Marx-Mariana Mazzucato also interprets Amazon's role as a pure means to an end for production capitalists; according to Mazzucato, Amazon is nothing but a "[...] commercial capitalist because it is a means by which production capitalists sell their goods and realize surplus value" (2018:53).

In this regard, much has changed since Karl Marx developed his diagnosis. Neither are we dealing with simple means and intermediaries, nor exclusively with the creation of markets and the possibility of controlling the access to and rules on this market. The problem is far more complex. I would consider it crucial to note that today's digital commercial capital, or 'merchant's capital'

- relieves itself-to a lesser or greater extent, depending on the specific business model - of the need to obtain goods (either with one's own or with borrowed funds) in order to then sell these goods at a surcharge, and instead profits from every single sales act achieved by others;

- attracts other sellers and production capital as well as large-scale investors in large numbers thanks to its promise of market expansion;

- is able to invest this superabundant capital in a permanent process of optimising the distributive forces;

- thereby promises to reduce the risk to the sales of others and guarantee sales more reliably than this would be possible through other sales channels;

- additionally generates such large amounts of data that-wherever this is deemed worthwhile-products can be offered for sale independently, with a guaranteed maximum surcharge.

This last point bears a risk which—as we could see before when we discussed the examples-most companies are probably well-aware of by now. Specifically, there 
is a risk, in the case of particularly successful surplus value realisation, of falling victim to this new type of digital merchant capital, which helped make that success possible in the first place. Why should production capital expose itself to this risk? After all, some 2.3 million active selling businesses offered their products for sale on Amazon in 2020, with one million new businesses joining that same year alone (see MarketplacePulse 2020). The pressure towards market expansion and surplus value realisation seems to be so great that this risk-which surely everybody hopes to be able to strategically minimise-is being taken.

Karl Marx also notes that merchant capital represents "a capital which shares in the profit without participating in its production" (Marx 1998: 283).. Yet that is not to say that merchant capital is purely unproductive or parasitic. On the contrary. Marx mentions another function of merchant capital, beyond market expansion: namely, the shortening of the circulation process. This is the period between actual value generation and successful value realisation. It is a "time during which capital does not produce at all, least of all surplus value" (ibid.: 279), a period which "restricts the creation of values". "Merchant's capital [...] may help indirectly to increase the surplus value produced by the industrial capitalists"; through market expansion, merchant capital drives the increasing division of labour among manufacturing enterprises and thus "the productivity of industrial capital, and its accumulation" (ibid.). In this instance, Marx speaks both of the business transactions between manufacturing companies (e.g. along value chains) and of the division of labour between those companies specialising in value generation and those specialising in value creation-i.e. he assumes a B2B perspective. "In so far as it shortens circulation time [...] [a]nd to the extent that it confines a smaller portion of capital to the sphere of circulation in the form of money capital, it [merchant capital] increases that portion of capital which is engaged directly in production." (ibid.)

Here, too, much seems to have changed since Marx. After all, those who possess particularly large amounts of excess capital invest considerable proportions of it precisely in digital merchant capital. This, in turn, facilitates the last step in the circulation process - that to the end customer-and thus the crucial step towards value realisation. This double promise is at the heart of Amazon's business model: maximum market expansion combined with a shorter circulation period and a simultaneous minimising of the corresponding costs. This is the only way of explaining why Amazon shares and investments have constantly-and increasingly-been valued far above those of the other GAFAM companies. The reason lies in the dual function that Amazon has for production capital. In this sense-if we were eager to attach a name or title to current capitalism-the term 'Amazon Capitalism' (see Alimahomed-Wilson et al. 2020) might prove the most appropriate. 